University of South Carolina

Scholar Commons

6-17-1996

\title{
Microstructure and Deposition Rate of Aluminum Thin Films from Chemical Vapor Deposition with Dimethylethylamine alane
}

\author{
Byoung-Youp Kim \\ Xiaodong Li \\ University of South Carolina - Columbia, lixiao@cec.sc.edu \\ Shi-Woo Rhee
}

Follow this and additional works at: https://scholarcommons.sc.edu/emec_facpub

Part of the Heat Transfer, Combustion Commons, and the Other Mechanical Engineering Commons

\section{Publication Info}

Published in Applied Physics Letters, Volume 68, Issue 25, 1996, pages \#3567-.

(c)Applied Physics Letters 1996, American Institute of Physics.

Kim, B-Y., Li, X., \& Rhee, S-W. (17 June 1996). Microstructure and Deposition Rate of Aluminum Thin Films from Chemical Vapor Deposition with Dimethylethylamine alane. Applied Physics Letters, 68 (25), \#3567. http://dx.doi.org/10.1063/1.116639

This Article is brought to you by the Mechanical Engineering, Department of at Scholar Commons. It has been accepted for inclusion in Faculty Publications by an authorized administrator of Scholar Commons. For more information, please contact digres@mailbox.sc.edu. 


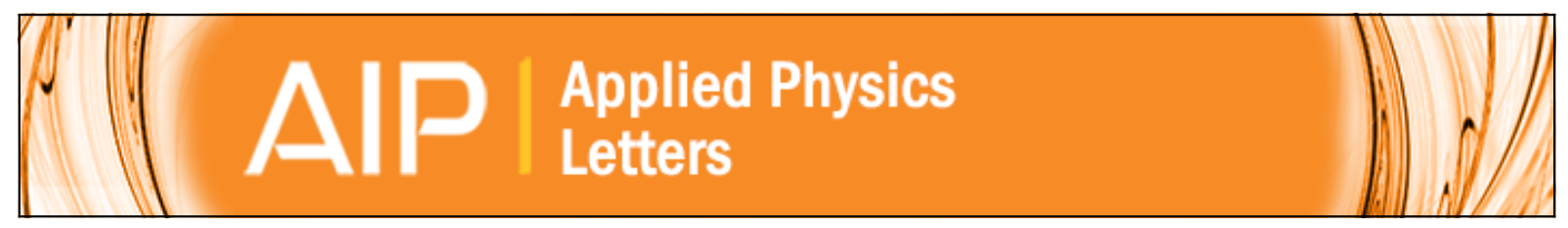

\section{Microstructure and deposition rate of aluminum thin films from chemical vapor deposition with dimethylethylamine alane}

ByoungYoup Kim, Xiaodong Li, and ShiWoo Rhee

Citation: Applied Physics Letters 68, 3567 (1996); doi: 10.1063/1.116639

View online: http://dx.doi.org/10.1063/1.116639

View Table of Contents: http://scitation.aip.org/content/aip/journal/apl/68/25?ver=pdfcov

Published by the AIP Publishing

\section{Articles you may be interested in}

Sticking coefficient and growth rate during Al chemical vapor deposition

Appl. Phys. Lett. 69, 4191 (1996); 10.1063/1.116982

Real time spectroellipsometry for optimization of diamond film growth by microwave plasmaenhanced chemical vapor deposition from $\mathrm{CO} / \mathrm{H} 2$ mixtures

J. Appl. Phys. 80, 6489 (1996); 10.1063/1.363668

Fluorinated amorphous carbon thin films grown by helicon plasma enhanced chemical vapor deposition for low dielectric constant interlayer dielectrics

Appl. Phys. Lett. 68, 2864 (1996); 10.1063/1.116350

Selective deposition of polycrystalline silicon thin films at low temperature by hotwire chemical vapor deposition Appl. Phys. Lett. 68, 2681 (1996); 10.1063/1.116280

Morphology and growth mode of Al films deposited by chemical vapor deposition from dimethylethylamine alane on $\mathrm{GaAs}(001) 2 \times 4$ surfaces

J. Vac. Sci. Technol. A 14, 1949 (1996); 10.1116/1.580366

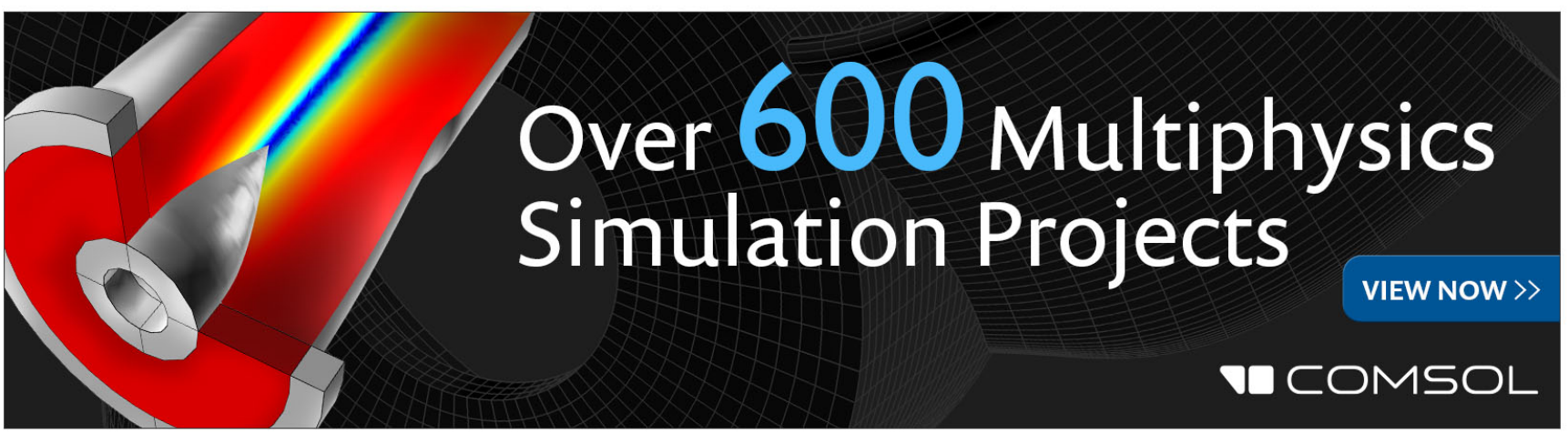




\title{
Microstructure and deposition rate of aluminum thin films from chemical vapor deposition with dimethylethylamine alane
}

\author{
Byoung-Youp Kim, ${ }^{\text {a) }}$ Xiaodong $\mathrm{Li}^{\mathrm{b}}{ }^{\mathrm{b}}$ and Shi-Woo Rhee ${ }^{\mathrm{c})}$ \\ Laboratory for Advanced Materials Processing (LAMP), Department of Chemical Engineering, Pohang \\ University of Science and Technology (POSTECH), Pohang 790-784, Korea
}

(Received 4 December 1995; accepted for publication 17 April 1996)

\begin{abstract}
Deposition of aluminum film from DMEAA in the temperature range of $100-300{ }^{\circ} \mathrm{C}$ has been studied. In this temperature range, there is a maximum deposition rate at around $150{ }^{\circ} \mathrm{C}$. The film deposited at $190^{\circ} \mathrm{C}$ has elongated blocklike grain shapes, which are $\sim 600 \mathrm{~nm}$ in width and $930 \mathrm{~nm}$ in length. Grains in the film deposited at $150{ }^{\circ} \mathrm{C}$ showed an equiaxed structure with grain size in the range of 100-300 nm in a film with $600 \mathrm{~nm}$ thickness. Aluminum oxide particle inclusion was observed especially at high deposition temperature. Plausible reaction pathways of DMEAA dissociation were suggested to explain the experimental observations. () 1996 American Institute of Physics. [S0003-6951(96)03825-9]
\end{abstract}

Aluminum has been widely used as a conducting material in the fabrication of integrated circuits. So far, most commercial Al films have been deposited by physical vapor deposition, but chemical vapor deposition usually gives more conformal coverage of a surface and allows a reactor design for multiwafer processing to give high throughput. For this reason, Al chemical vapor deposition (CVD) has been actively investigated for ULSI applications like $256 \mathrm{Mbit}$ or 1 Gbit DRAM fabrication.

Previous works related to Al CVD precursors and reaction mechanisms have been reviewed comprehensively by Simmonds and Gladfelter. ${ }^{1}$ For the deposition of aluminum, alkyl aluminum and amine-alane adducts have been used extensively. DMEAA, an adduct of alane $\left(\mathrm{AlH}_{3}\right)$ and dimethylethylamine $\left[\mathrm{N}\left(\mathrm{CH}_{3}\right)_{2} \mathrm{C}_{2} \mathrm{H}_{5}\right]$, is the most recently introduced member of the amine family of precursors. Its relatively high vapor pressure at room temperature (1.5 Torr), its long shelf life, its ability to deposit carbon contamination-free films, combined with the advantages of being a liquid have recently made it the precursor of attention. The deposition behavior and chemistry of DMEAA, ${ }^{2}$ have been studied including selective deposition ${ }^{3,4}$ but study of the microstructure of Al films and data related to the deposition rate and chemical reaction kinetics is still lacking.

In this letter, experimental results, mainly the deposition rate and microstructure of the film as a function of deposition temperature, obtained from chemical vapor deposition of aluminum with DMEAA are described.

CVD of aluminum was carried out in a homemade, low pressure, cold wall, single wafer reactor. DMEAA was introduced directly without a carrier gas through vapor phase mass flow controller, MKS mass-flo type 1150. DMEAA with a rate of $0.01 \mathrm{ml} / \mathrm{min}$ in liquid volume was introduced from above through a cylindrical showerhead-type distributor and flowed down vertically toward the wafer surface. The gap distance between the showerhead and the susceptor was $3 \mathrm{~cm}$. Al film was deposited on various substrate surfaces

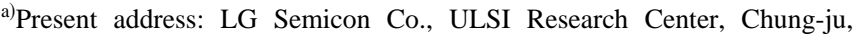
Korea.

${ }^{b)}$ Present address: Department of Mechanical Engineering, Ohio State University, Columbus, OH 43210.

${ }^{c}$ Electronic mail: srhee@ vision.postech.ac.kr
}

such as $\mathrm{TiN}, \mathrm{Al}, \mathrm{Si}$, and $\mathrm{SiO}_{2}$ with deposition temperature between 100 and $300{ }^{\circ} \mathrm{C}$ and pressure at 0.2 mbar. The base pressure before the deposition was $1.5 \times 10^{-6}$ mbar. A substrate surface of TiN and Al was sputter deposited on a silicon wafer and the $\mathrm{SiO}_{2}$ surface was obtained by thermal oxidation of a silicon wafer.

Figure 1 shows the amount of $\mathrm{Al}$ deposited on various substrate surfaces as a function of deposition time at a deposition temperature of $200{ }^{\circ} \mathrm{C}$. The induction time, during which no appreciable deposition had been observed, was quite long on $\mathrm{Si}$ and $\mathrm{SiO}_{2}$ surfaces. In that case, discontinuous film was formed and adhesion was very poor. On the TiN and Al surface, induction time was negligible and adhesion was good. From this observation, we could conclude that selective deposition is possible on $\mathrm{TiN}$ or $\mathrm{Al}$ over the $\mathrm{Si}$ or $\mathrm{SiO}_{2}$ surface. As the deposition temperature goes up, the induction time becomes shorter and it becomes more difficult to achieve selective deposition. As the surface is covered with $\mathrm{Al}$, the slope, i.e., the deposition rate, should be the same regardless of the substrate surface, but it seems that depending on the nucleation behavior at the initial stage, the deposition rate is slightly different.

Figure 2 shows the deposition rate of $\mathrm{Al}$ film on the TiN surface as a function of deposition temperature. The deposition rate increased to a maximum at around $150{ }^{\circ} \mathrm{C}$ and then

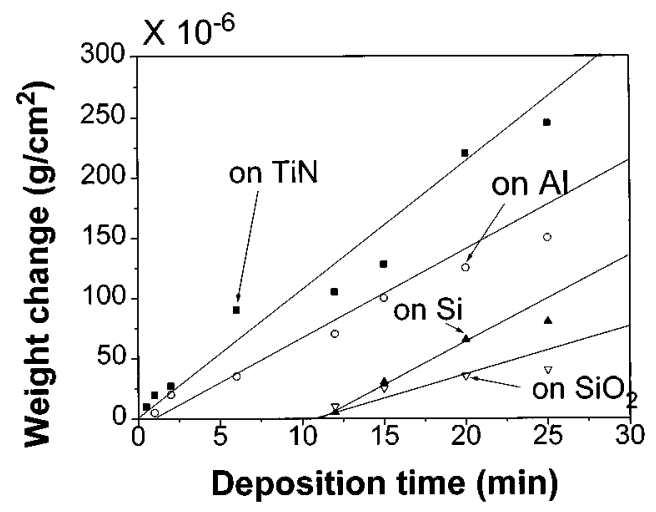

FIG. 1. Amount of $\mathrm{Al}$ deposited on various substrate surfaces as a function of deposition time at a deposition temperature of $200{ }^{\circ} \mathrm{C}$ and a pressure of 0.2 mbar. 


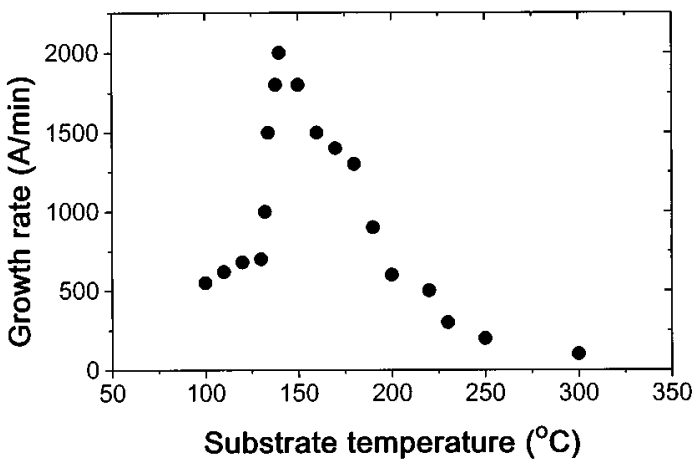

FIG. 2. Deposition rate of Al film on TiN surface as a function of deposition temperature.

decreased with the substrate temperature above $150{ }^{\circ} \mathrm{C}$. It appears that DMEAA is very sensitive to the reaction temperature in this temperature range and gas phase reaction might become dominant when the deposition temperature is higher than $150{ }^{\circ} \mathrm{C}$. It was reported that the mechanism in the deposition of $\mathrm{Al}$ from TMAA involved the adsorption of amine-alane adducts, dissociation of amine, and alane on the surface, dissociation of alane, deposition of $\mathrm{Al}$, and desorption of hydrogen molecule. ${ }^{5}$ The deposition of $\mathrm{Al}$ from DMEAA can be written as
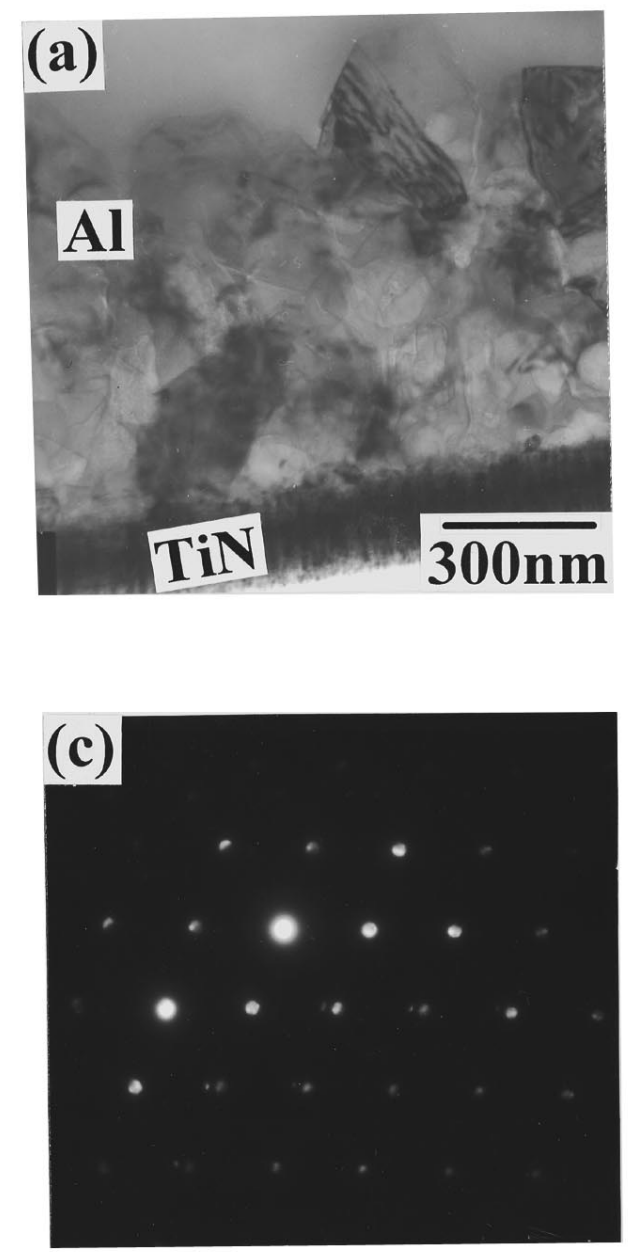

$$
\begin{aligned}
{\left[\left(\mathrm{CH}_{3}\right)_{2} \mathrm{C}_{2} \mathrm{H}_{5} \mathrm{~N}\right] \mathrm{AlH}_{3}(\mathrm{~g}) \rightarrow[} & \left.\left(\mathrm{CH}_{3}\right)_{2} \mathrm{C}_{2} \mathrm{H}_{5} \mathrm{~N}\right] \mathrm{AlH}_{3}(\mathrm{ads}), \\
{\left[\left(\mathrm{CH}_{3}\right)_{2} \mathrm{C}_{2} \mathrm{H}_{5} \mathrm{~N}\right] \mathrm{AlH}_{3}(\mathrm{ads}) \rightarrow } & \mathrm{AlH}_{3}(\mathrm{ads}) \\
& +\left(\mathrm{CH}_{3}\right)_{2} \mathrm{C}_{2} \mathrm{H}_{5} \mathrm{~N}(\text { ads }),
\end{aligned}
$$

$\mathrm{AlH}_{3}($ ads $) \rightarrow \mathrm{Al}($ ads $)+3 \mathrm{H}($ ads $)$,

$3 \mathrm{H}($ ads $) \rightarrow 1.5 \mathrm{H}_{2}(\mathrm{~g})$,

$\left[\left(\mathrm{CH}_{3}\right)_{2} \mathrm{C}_{2} \mathrm{H}_{5} \mathrm{~N}\right](\mathrm{s}) \rightarrow\left[\left(\mathrm{CH}_{3}\right)_{2} \mathrm{C}_{2} \mathrm{H}_{5} \mathrm{~N}\right](\mathrm{g})$,

as suggested by Han et al. ${ }^{6}$

For TMMA, the deposition rate was indicated to be controlled by reaction (2), the dissociation of amine-alane adducts on the surface, ${ }^{5}$ whereas hydrogen desorption was proposed to be the rate limiting step for TEAA. ${ }^{7}$ Han et al. suggested that DMEAA was likely to follow a behavior between those of TMAA and TEAA. ${ }^{6}$

We believe that, at substrate temperatures lower than $150{ }^{\circ} \mathrm{C}$, adsorption of the precursor and surface chemical reactions were mainly involved in the deposition of aluminum and the deposition rate increased with increasing deposition temperature. We also believe that the amine-alane adduct can be dissociated in the gas phase as follows when the temperature is high enough. This may be the case when the substrate temperature is higher than $150{ }^{\circ} \mathrm{C}$ :
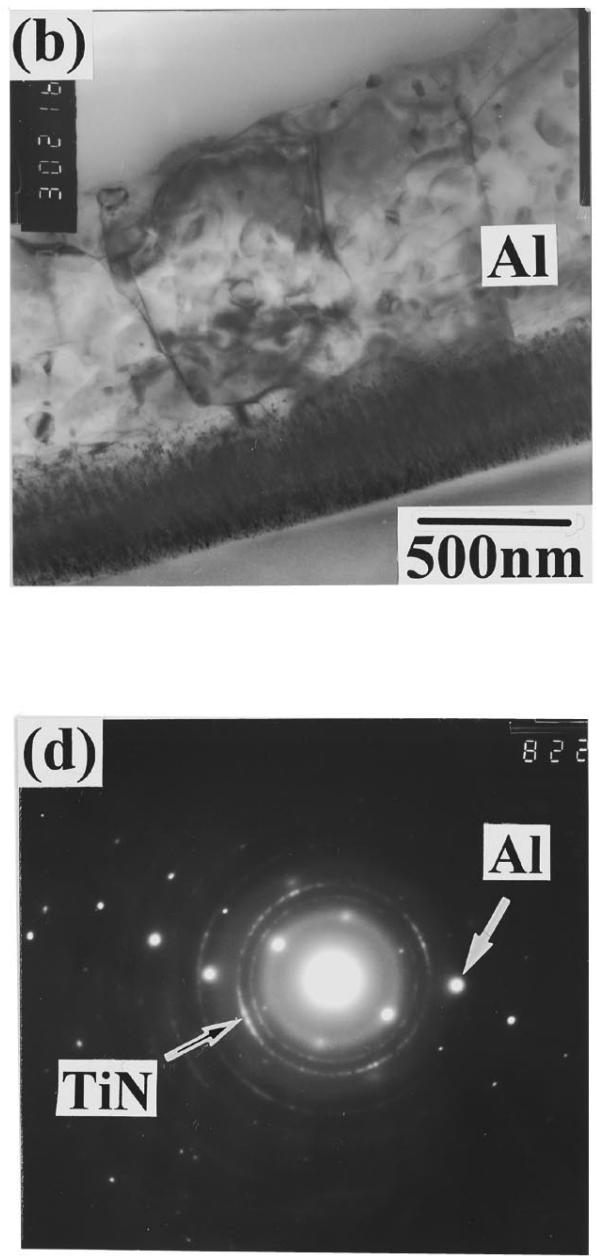

FIG. 3. Cross sectional TEM micrographs of the films deposited (a) at $150{ }^{\circ} \mathrm{C}$ and (b) at $190{ }^{\circ} \mathrm{C}$. Selected area diffraction pattern of (c) Al grain and (d) $\mathrm{Al} / \mathrm{TiN}$ interface in the film deposited at $150^{\circ} \mathrm{C}$. 

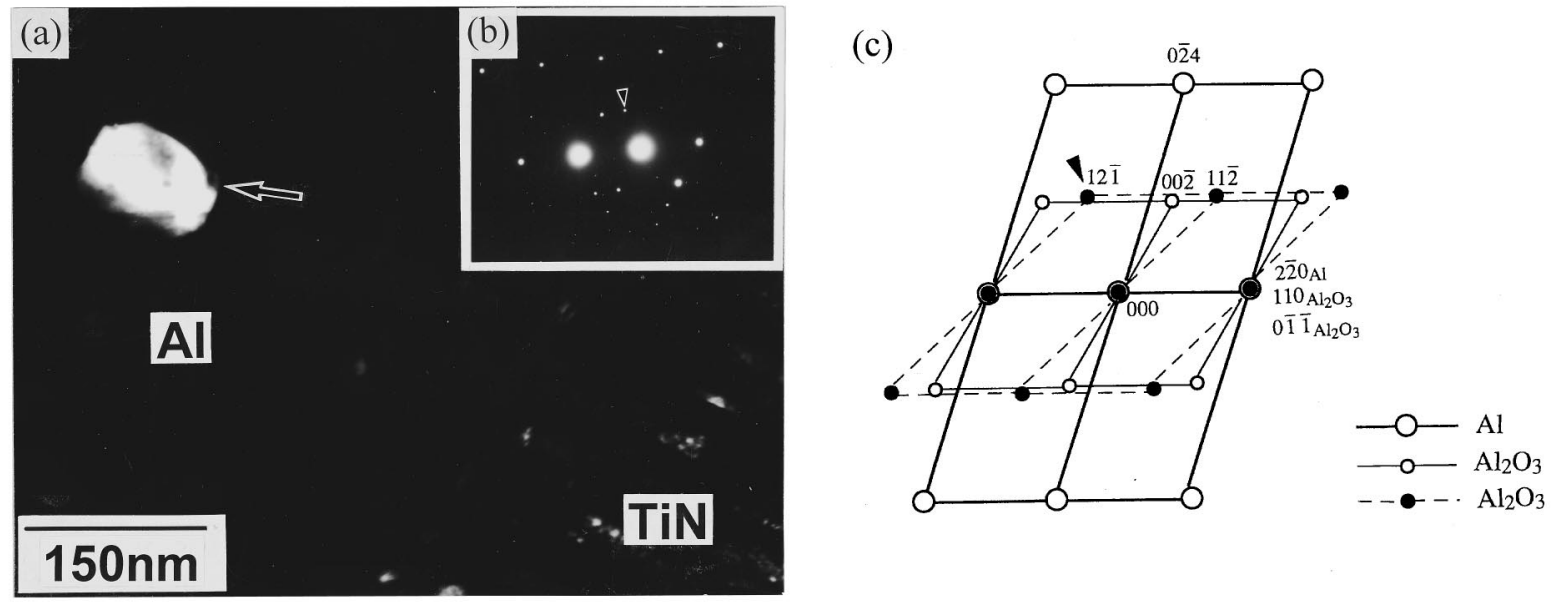

FIG. 4. (a) Aluminum oxide particle imbedded in the aluminum grain in the film deposited at $190{ }^{\circ} \mathrm{C}$, (b) diffraction pattern, and (c) computer simulated pattern for the aluminum oxide particles. The dark field TEM image was taken from the spot indicated by the arrow.

$$
\begin{aligned}
{\left[\left(\mathrm{CH}_{3}\right)_{2} \mathrm{C}_{2} \mathrm{H}_{5} \mathrm{~N}\right] \mathrm{AlH}_{3}(\mathrm{~g}) \rightarrow } & \mathrm{AlH}_{3}(\mathrm{~g}) \\
& +\left(\mathrm{CH}_{3}\right)_{2} \mathrm{C}_{2} \mathrm{H}_{5} \mathrm{~N}(\mathrm{~g}) .
\end{aligned}
$$

It has been reported that powders were formed in the gas phase from DMEAA when the temperature is higher than $170{ }^{\circ} \mathrm{C} .{ }^{2,8}$ Alane is known to be unstable and forms a dimer, trimer, and even a polymer. ${ }^{9}$ In a cold wall reactor used in this experiment, the temperature gradient exists between the hot substrate and the cold reactor wall and the gas phase can be heated by a hot substrate. When the substrate temperature is higher than $150^{\circ} \mathrm{C}$, the gas phase temperature is high enough so that part of DMEAA is presumably dissociated in the gas phase, as given in reaction (6), to form alane. Alane can be readily polymerized which, we believe, is not readily adsorbed on the surface to form aluminum film. The deposition rate above $250^{\circ} \mathrm{C}$ is very low because gas phase reaction becomes very active. More study is needed to clarify this reaction pathway.

Another possibility is homogeneous nucleation through which powders are formed and precursors are consumed in the gas phase. Alane formed in the gas phase by reaction (6) may nucleate into a powder. In general, the deposition rate is decreased when there is powder formation and in this case, powders can be collected on the reactor wall after the deposition but we did not detect an appreciable amount of powders in our experiment.

The films deposited on TiN were polycrystalline with no detectable impurities as measured by AES. Figures 3(a) and 3(b) shows the cross sectional TEM micrographs of the films deposited at 150 and $190{ }^{\circ} \mathrm{C}$. The film deposited at $190{ }^{\circ} \mathrm{C}$ shows that grains have elongated blocklike shapes, which are $\sim 600 \mathrm{~nm}$ in width and $930 \mathrm{~nm}$ in height. It was also found that some grains formed at the nucleation stage at the interface were smaller. On the other hand, grains in the film deposited at $150{ }^{\circ} \mathrm{C}$ showed an equiaxed structure with grain size in the range of $100-300 \mathrm{~nm}$ in a film with $600 \mathrm{~nm}$ thickness. The grains formed at $150{ }^{\circ} \mathrm{C}$ were smaller and it may be due to the fact that the deposition rate is faster at $150{ }^{\circ} \mathrm{C}$ or the bulk diffusion is not fast enough for the grains to grow at this temperature. The preferred orientation of $\mathrm{Al}$ was confirmed to be $\langle 111\rangle$ in the growth direction of the film and this may be due to the $\langle 111\rangle$ preferential orientation of TiN (Ref. 10) on the silicon substrate as shown in Figs. 3(c) and $3(\mathrm{~d})$.

We could also detect small particle inclusions imbedded in the aluminum grain in the film deposited at $190{ }^{\circ} \mathrm{C}$ and it was confirmed to be the aluminum oxide particle from the selective area diffraction pattern as shown in Fig. 4. We could not detect particle inclusions in the film deposited at $150{ }^{\circ} \mathrm{C}$. These particles are not likely to be formed by the precipitation in the solid phase but more likely to be formed in the gas phase and incorporated into the film. It was pointed out that impurities such as $\mathrm{H}_{2} \mathrm{O}, \mathrm{O}_{2}$, or $\mathrm{CO}$ caused an increase in the number of particles formed in the gas phase. ${ }^{6}$ We believe that at higher temperatures above $150{ }^{\circ} \mathrm{C}$, it is more likely that residual impurity gases react to form particles. Also, alane formed by the gas phase dissociation of the adduct is more likely to react with impurity. For example, with oxygen, alane can react as

$$
2 \mathrm{AlH}_{3}+3 / 2 \mathrm{O}_{2} \rightarrow \mathrm{Al}_{2} \mathrm{O}_{3}+3 \mathrm{H}_{2} \text {. }
$$

The oxide particle formation at high deposition temperatures is not believed to cause the decrease in the deposition rate, because the oxide powder formation is not intensive.

This research was supported by LG Semicon. Co., and the support of the Engineering Research Center for Interface Science and Technology of Materials is also acknowledged.

${ }^{1}$ M. G. Simmonds and W. L. Gladfelter, in The Chemistry of Metal CVD, edited by T. Kodas and M. J. Hampden-Smith (VCH, Weinheim, 1994).

${ }^{2}$ M. G. Simmonds, W. L. Gladfelter, R. Nagaraja, W. W. Szymanski, K.-H. Ahn, and P. H. McMurry, J. Vac. Sci. Technol. A 9, 2782 (1991).

${ }^{3}$ W. L. Gladfelter, Chem. Mater. 5, 1372 (1993).

${ }^{4}$ M. G. Simmonds, I. Taupin, and W. L. Gladfelter, Chem. Mater. 6, 935 (1994)

${ }^{5}$ L. H. Dubois, B. R. Zegarski, C.-T. Kao, and R. G. Nuzzo, Surf. Sci. 236, 77 (1990).

${ }^{6}$ J. Han, K. F. Jensen, Y. Senzaki, and W. L. Gladfelter, Appl. Phys. Lett. 64, 425 (1994).

${ }^{7}$ L. H. Dubois, B. R. Zegarski, M. E. Gross, and R. G. Nuzzo, Surf. Sci. 244, 89 (1991).

${ }^{8}$ M. G. Simmonds, W. L. Gladfelter, H. Li, and P. H. McMurry, J. Vac. Sci. Technol. A 11, 3026 (1993).

${ }^{9}$ J. W. Turley and H. W. Rinn, Inorg. Chem. 8, 18 (1969).

${ }^{10}$ X. Li, B.-Y. Kim, and S. Rhee, Appl. Phys. Lett. 67, 3426 (1995). 